\title{
Clinical illness and outcomes in Nigerian children with persistent early-appearing anaemia following initiation of artemisinin-based combination treatments of uncomplicated falciparum malaria
}

Kazeem Akano ${ }^{1,2,3}$, Bayo Fatunmbi ${ }^{4}$, Godwin Ntadom ${ }^{1,5}$, Adejumoke I. Ayede ${ }^{6}$, Temitope Aderoyeje ${ }^{7}$, Adewale Bakre ${ }^{5}$, Omobolaji T. Alebiosu ${ }^{5}$, Odafe Akpoborie ${ }^{5}$, Chukwuebuka Okafor ${ }^{5}$, Grace O. Gbotosho ${ }^{5,8}$, Onikepe A. Folarin ${ }^{2}$, Joy C. Ebenebe ${ }^{1,9}$, Jose Ambe ${ }^{1,10}$, Robinson Wammanda ${ }^{1,11}$, Nma Jiya ${ }^{1,12}$, Finomo Finomo ${ }^{1,13}$, George Emechebe ${ }^{1,14}$, Olugbenga Mokuolu ${ }^{1,15}$, Chimere Agomo ${ }^{1,16}$, Stephen Oguche ${ }^{1,17}$, Christian Happi ${ }^{1,2}$, and Akintunde Sowunmi ${ }^{1,3,5,7, *}$

${ }^{1}$ Antimalarial Therapeutic Efficacy Monitoring Group, National Malaria Elimination Programme, The Federal Ministry of Health, Abuja 900211, Nigeria

2 Department of Biological Sciences and African Centre of Excellence for Genomics of Infectious Diseases (ACEGID), Redeemer's University, Ede 232102, Nigeria

3 Institute for Medical Research and Training, College of Medicine, University of Ibadan, Ibadan 200212, Nigeria

${ }_{5}^{4}$ World Health Organization, Country Office, Kampala, Uganda

5 Department of Pharmacology and Therapeutics, College of Medicine, University of Ibadan, Ibadan 200284, Nigeria

${ }^{6}$ Department of Paediatrics, University of Ibadan, Ibadan 200284, Nigeria

7 Department of Clinical Pharmacology, University College Hospital, Ibadan 200212, Nigeria

8 Department of Pharmacology and Toxicology, Faculty of Pharmacy, University of Ibadan, Ibadan 200284, Nigeria

9 Department of Paediatrics, Nnamdi Azikiwe University, Awka 420110, Nigeria

${ }^{10}$ Department of Paediatrics, University of Maiduguri, Maiduguri 600230, Nigeria

11 Department of Paediatrics, Ahmadu Bello University, Zaria 810001, Nigeria

12 Department of Paediatrics, Usman Dan Fodio University, Sokoto 840001, Nigeria

${ }^{13}$ Department of Paediatrics, Federal Medical Centre, Yenagoa 560231, Nigeria

${ }^{14}$ Department of Paediatrics, Imo State University Teaching Hospital, Orlu 473212, Nigeria

15 Department of Paediatrics and Child Health, University of Ilorin, Ilorin 240003, Nigeria

16 Department of Medical Laboratory Science, University of Lagos, Lagos 100254, Nigeria

17 Department of Paediatrics, University of Jos, Jos 930222, Nigeria

Received 22 March 2019, Accepted 21 August 2019, Published online 13 September 2019

\begin{abstract}
In non-anaemic children with malaria, early-appearing anaemia (EAA) is common following artemisininbased combination treatments (ACTs) and it may become persistent (PEAA). The factors contributing to and kinetics of resolution of the deficit in haematocrit from baseline (DIHFB) characteristic of ACTs-related PEAA were evaluated in 540 consecutive children with malaria treated with artemether-lumefantrine, artesunate-amodiaquine or dihydroartemisinin-piperaquine. Asymptomatic PEAA occurred in 62 children. In a multiple logistic regression model, a duration of illness $\leq 3$ days before presentation, haematocrit $<35 \%$ before and $<25 \%$ one day after treatment initiation, drug attributable fall in haematocrit $\geq 6 \%$, and treatment with dihydroartemisinin-piperaquine independently predicted PEAA. Overall, mean DIHFB was 5.7\% (95\% CI 4.8-6.6) 7 days after treatment initiation and was similar for all treatments. Time to $90 \%$ reduction in DIHFB was significantly longer in artemether-lumefantrine-treated children compared with other treatments. In a one compartment model, declines in DIHFB were monoexponential with overall mean estimated half-time of 3.9 days (95\% CI 2.6-5.1), Cmax of 7.6\% (95\% CI 6.7-8.4), and Vd of $0.17 \mathrm{~L} / \mathrm{kg}$ (95\% CI 0.04-0.95). In Bland-Altman analyses, overall mean anaemia recovery time (AnRT) of 17.4 days (95\% CI 15.5-19.4) showed insignificant bias with 4, 5 or 6 multiples of half-time of DIHFB. Ten children after recovery from PEAA progressed to late-appearing anaemia (LAA). Progression was associated with female gender and artesunateamodiaquine treatment. Asymptomatic PEAA is common following ACTs. PEAA or its progression to LAA may have implications for case and community management of anaemia and for anaemia control efforts in sub-Saharan Africa where ACTs have become first-line antimalarials.
\end{abstract}

*Corresponding author: akinsowunmi@hotmail.com

This is an Open Access article distributed under the terms of the Creative Commons Attribution License (https://creativecommons.org/licenses/by/4.0), which permits unrestricted use, distribution, and reproduction in any medium, provided the original work is properly cited. 
Key words: Persistent early-appearing anaemia, Falciparum malaria, Artemisinin-based combination treatments, Children, Nigeria.

\footnotetext{
Résumé - Clinique et évolution de l'anémie persistante d'apparition précoce chez les enfants nigérians, après traitement combiné à base d'artémisinine du paludisme non compliqué à Plasmodium falciparum. Chez les enfants impaludés non anémiques, une anémie d'apparition précoce (AAP) est fréquente après un traitement par une combinaison à base d'artémisinine (CTA) et peut devenir persistante (AAPP). Les facteurs contribuant à la résolution du déficit en hématocrite par rapport aux valeurs initiales (DHPVI), caractéristique de l'AAPP liée aux CTA, ont été évalués chez 540 enfants impaludés traités par artéméther-luméfantrine, artésunate-amodiaquine ou dihydroartémisininepipéraquine. Une AAPP asymptomatique est survenue chez 62 enfants. Dans un modèle de régression logistique multiple, une durée de la maladie $\leq 3$ jours avant la présentation, un hématocrite $<35 \%$ avant et $<25 \%$ un jour après le début du traitement, une chute attribuable au médicament $\geq 6 \%$ et un traitement par dihydroartémisinine-pipéraquine prédisent l'AAPP de manière indépendante. Globalement, le DHPVI moyen était de 5,7\% (IC à $95 \%$ de 4,8 à 6,6) 7 jours après le début du traitement et était similaire pour tous les traitements. Le temps de réduction de $90 \%$ du DHPVI était significativement plus long chez les enfants traités à l'artéméther-luméfantrine que pour les autres traitements. Dans un modèle à un compartiment, les baisses de DHPVI étaient monoexponentielles avec une demi-durée moyenne globale estimée à 3,9 jours (IC $95 \%$ 2,6-5,1), une Cmax de 7,6 \% (IC $95 \%$ 6,7-8,4), et une Vd de 0,17 L/kg. (IC $95 \%$ 0,04-0,95). Dans les analyses de Bland-Altman, le temps moyen de récupération de l'anémie totale de 17,4 jours (IC à $95 \%$ de 15,5 à 19,4) a montré un biais non significatif avec 4, 5 ou 6 multiples de la moitié de la demi-vie du DHPVI. Dix enfants après convalescence de AAPP ont évolué vers une anémie tardive. La progression était associée au sexe féminin et au traitement par l'artésunate-amodiaquine. L'AAPP asymptomatique est courante après les CTA. L'AAPP ou sa progression vers l'anémie tardive peut avoir des implications pour la gestion individuelle ou communautaire des cas d'anémie et pour les efforts de contrôle de l'anémie en Afrique subsaharienne où les CTA sont devenus des antipaludéens de première ligne.
}

\section{Abbreviations}

$\% \quad$ Percent

${ }^{\circ} \mathrm{C} \quad$ Degree Celsius

AA Artesunate-amodiaquine

ACPR Adequate clinical and parasitological response

ACTs Artemisinin-based combination treatments

AL Artemether-lumefantrine

ANOVA Analysis of variance

AOR Adjusted odds ratio

$\mathrm{AUC}_{\text {dihfb }}$ Area under the curve of the deficit in haematocrit from baseline versus time

AnRT Anaemia recovery time

CI Confidence interval

$\mathrm{CLp}_{\text {dihfb }}$ Plasma clearance of the deficit in haematocrit from baseline

$\mathrm{Cmax}_{\text {dihfb }}$ Maximum deficit in haematocrit from baseline

DAFH Drug-attributable fall in haematocrit

DHP Dihydroartemisinin-piperaquine

DIHFB Deficit in haematocrit from baseline

dL Deciliter

EAA Early-appearing anaemia

FCT Fever clearance time

g Gram

GMPD Geometric mean parasite density

$\mathrm{Hb} \quad$ Haemoglobin

HCT Haematocrit

$K_{\text {eldihfb }} \quad$ Elimination rate constant of deficit in haematocrit from baseline

$K_{\text {eldiHbfb }}$ Elimination rate constant of deficit in haemoglobin from baseline

$\mathrm{kg}$

Kilogram

$\begin{array}{ll}\text { L } & \text { Litre } \\ \text { LAA } & \text { Late-appearing anaemia } \\ \text { OR } & \text { Odds ratio } \\ \text { PADH } & \text { Post-artesunate delayed haemolysis } \\ \text { PCR } & \text { Polymerase chain reaction } \\ \text { PCT } & \text { Parasite clearance time } \\ \text { PEAA } & \text { Persistent early-appearing anaemia } \\ \text { PRR } & \text { Parasite reduction ratio } \\ t_{1 / 2 \text { dihfb }} & \text { Half-time of deficit in haematocrit from baseline } \\ t_{1 / 2 \text { diHbfb }} & \text { Half-time of deficit in haemoglobin from baseline } \\ T_{50 \text { dihfb }} & \text { Time to } 50 \% \text { reduction of deficit in haematocrit from } \\ & \text { baseline } \\ T_{90 \text { dihfb }} & \text { Time to } 90 \% \text { reduction of deficit in haematocrit from } \\ T_{\text {max }} & \text { baseline } \\ & \begin{array}{l}\text { Time to reach maximum deficit in haematocrit from } \\ \text { baseline }\end{array} \\ \mathrm{Vd}_{\mathrm{diHbfb}} & \text { Volume of the distribution of the deficit in haemoglobin } \\ & \text { from baseline } \\ \mu \mathrm{L} & \text { Microliter }\end{array}$

\section{Introduction}

Falciparum malarial anaemia, one of the inevitable consequences of untreated and treated infections, is a public health problem in many malaria endemic areas of the world $[6,11$, $12,14,18,21,22]$. Although intravenous artesunate or artemisinin-based combination treatments (ACTs) have remained efficacious treatments for severe or uncomplicated falciparum malaria, treatment is associated with delayed haemolytic anaemia (post-artesunate delayed haemolysis [PADH] syndrome) in severe malaria in immunologically naïve adults $[3,9,10,16$, $28,30]$, or a relatively asymptomatic late-appearing anaemia 
(LAA) in uncomplicated infections in children [19]. Treatment may also be associated with an early-appearing anaemia (EAA) in children who are not anaemic before treatment initiation [19] and it may persist for up to one or more weeks after treatment initiation - persistent early-appearing anaemia (PEAA). Recovery from PEAA is common but it can progress after recovery to LAA [21].

ACT-related PEAA has not been broadly evaluated clinically or parasitologically, and its relationship to LAA has not been frequently explored in young African children. Additionally, little is known about the time-course of the deficit in haematocrit characteristic of ACT-related PEAA. Clinical and parasitological evaluation, and evaluation of the time-course of PEAA may assist in the management of individual patients and contribute to community management of malaria- and antimalarial-related anaemia in young African children.

In a previous study, we described the clinical illness and outcomes in children with LAA following ACTs of uncomplicated falciparum malaria [19]. In the present study, we describe the clinical illness and outcomes in Nigerian children with PEAA following initiation of ACTs of uncomplicated falciparum malaria. The main aims of our study were: to determine the frequency, and the factors contributing to PEAA and to evaluate the time-course of the deficit in haematocrit characteristic of ACT-related PEAA following initiation of treatment with artemether-lumefantrine (AL), artesunate-amodiaquine (AA) or dihydroartemisinin-piperaquine (DHP). Additional aims were to determine the relationship between anaemia recovery time (AnRT) and the half-time of the deficit in haematocrit in children with ACT-related PEAA, and the time-course of progression from PEAA to LAA.

\section{Patients and methods}

\section{Study design}

The study took place between June 2014 and September 2015. It was part of a larger study to monitor therapeutic efficacies of AL, AA and DHP in <5-year-old children with malaria living in six geographical areas of Nigeria. The details of the therapeutic efficacies have been reported elsewhere [7]. The present study is a consecutive study of all $<5$-year-old children with uncomplicated falciparum malaria who satisfied the criteria for the definition of persistent early appearing anaemia (PEAA) following treatment with ACTs (see below).

\section{Study procedures}

Patients were eligible to participate in the study if they were aged 6-59 months, had symptoms compatible with acute uncomplicated malaria and Plasmodium falciparum monoinfections between 2000 and $200,000 \mu \mathrm{L}^{-1}$ of blood, had no history of antimalarial drug intake in the 2 weeks preceding enrolment, and no evidence of severe malaria [25, 29], and parents or guardians gave written informed consent. Patients were randomised to $\mathrm{AL}, \mathrm{AA}$ or DHP treatments for 3 days (day 0-2), as previously described [7]. The day of presentation (day of treatment initiation) was regarded as day 0 . Thick and thin blood films were obtained from each child as soon as they came to the clinic and the slides were carefully labelled with the patients' codes and air-dried before being Giemsa-stained. Routine clinical and parasitological evaluations were done at enrolment and during follow-up on days $1-3$ or $1-4,7,14$, $21,28,35$ and 42 , as previously described [7].

\section{Haematological evaluation}

Capillary blood obtained from a finger prick was collected before treatment and during follow-up, and was used to measure haematocrit using a microhaematocrit tube and microcentrifuge (Hawksley, Lancing, UK). Anaemia was defined as haematocrit $<30 \%$ and was further classified as mild, moderate or severe if haematocrit was $21-29,15-<21$ or $<15 \%[14,21]$. LAA was diagnosed as previously described using the following criteria: adequate clinical and parasitological response (ACPR) [26] occurring within 1 week, haematocrit $\geq 30 \%$ at 1 and/or 2 weeks, a fall in haematocrit to $<30 \%$ occurring at 3-6 weeks, absence of concomitant illness at 1-6 weeks, and absence of asexual parasitaemia by both microscopy and PCR at 1-6 weeks [19]. In patients who had PEAA or LAA, AnRT was defined as time from appearance of, to recovery from, anaemia [19]. Drug-attributable fall in haematocrit (DAFH) was defined as the difference between pre-treatment and the lowest recorded haematocrit values in the first week after initiation of treatment $[21,22]$.

\section{Evaluation of responses to treatment}

Response to drug treatment was assessed using a modified version of the World Health Organization in vivo clinical classification criteria [26, 27] and other outcome measures, as previously described [7, 13]. Briefly, the outcome measures include asexual parasite positivity on day 1 or 2 after treatment initiation, parasite reduction ratio 1 or 2 days after treatment initiation, parasite clearance time and time to recovery from anaemia.

\section{Definition of persistent early-appearing anaemia (PEAA)}

Haematocrit $<30 \%$ within 2 days of treatment initiation in a patient who was not anaemic at presentation and its persistence for at least 7 days in the absence of any concomitant illness, was regarded as (PEAA).

\section{Evaluation of the kinetics of the disposition of the deficit in haematocrit from baseline (DIFHB) in children with PEAA}

Patients were evaluated using modified conventional kinetic parameters if they were: non-anaemic at enrolment (haematocrit $\geq 30 \%$ before treatment); developed anaemia within 1-2 days following initiation of treatment and remained anaemic until 1 week after treatment initiation, that is, from days 1 or 2 to day 7 , and blood was obtained daily for haematocrit estimation on at least five occasions between days $1-7$. Because haematocrit values at presentation were normal in all patients, deficits 
in haematocrit values from day 1 or 2 after treatment initiation until haematocrit values returned to normal were subtracted from the baseline haematocrit values. Area under the curve of the deficit in haematocrit from baseline (DIHFB) versus time $\left(\mathrm{AUC}_{\mathrm{dihfb}}\right)$ was estimated by the trapezoidal method, as previously described [20, 23]. Plasma clearance of DIHFB (that is, recovery from the anaemia) was estimated from the equation: $\mathrm{CLp}_{\text {dihfb }}=$ Haematocrit concentration at time 0 (pre-treatment) $/$ AUC $_{\text {dihfb }}$ where CLp $p_{\text {dihfb }}$ is the volume of blood completely cleared of the deficit in haematocrit/day. $K_{\text {eldihfb }}$ was estimated from the equation $K_{\text {eldihfb }}=0.693 / t_{1 / 2 \mathrm{dihfb}}$, where $K_{\text {eldihfb }}$ is the elimination rate constant and $t_{1 / 2 \text { dihfb }}$ is the half-time of DIHFB. For estimation of the volume of distribution of DIHFB, haematocrit values were converted to haemoglobin values by dividing the values by a factor of three, as suggested by Bain and Bates [1]. The volume of distribution of the deficit in haemoglobin $\left(\mathrm{Vd}_{\mathrm{diHbfb}}\right)$ was estimated from the equation: $\mathrm{Vd}_{\mathrm{diHbfb}}=\mathrm{CLp}_{\mathrm{diHbfb}} / K_{\text {eldiHbfb }}$.

\section{Statistical analysis}

Data were analysed using version 6 of Epi-Info software [8] and the statistical program SPSS for Windows version 20.0 [24]. Proportions were compared by calculating $\chi^{2}$ using Yates' correction, Fisher's exact or Mantel Haenszel tests. Normally distributed, continuous data were compared by Student's $t$-test and analysis of variance (ANOVA) or by paired $t$-test. Univariate analysis and stepwise multiple logistic regression models were used to test the association between clinical, parasitological or haematological parameters and PEAA, and to evaluate independent predictors of PEAA, respectively. Relationships between two variables that are continuous and normally distributed and those that are discrete and not normally distributed were evaluated by Pearson's correlation coefficient and Spearman's correlation coefficient, respectively. Agreement between AnRT and multiples of half-time of DIHFB was assessed by Bland-Altman analysis [2]. Values of $p<0.05$ were taken to indicate significant differences. Data were double entered serially using patient codes and were only analysed at the end of the study.

\section{Ethics approval and consent to participate}

The study protocol from which the dataset was derived was approved by the National Health Research Ethics Committee, Abuja, Nigeria [NHREC/01/01/2007-22/10/2014]. A written informed consent was obtained from the parents or guardians of the children.

\section{Results}

\section{Characteristics of patients at enrolment}

During the study period, 6713 children with symptoms suggestive of uncomplicated falciparum malaria were screened for P. falciparum. Parasitaemia was present in 2410 children; 540 children had haematocrit values $\geq 30 \%$ before treatment initiation (Fig. 1). The baseline characteristics of the children with PEAA are summarised in Table 1. Compared to children without PEAA, children with PEAA were significantly younger, weighed significantly less, presented with a history of significantly shorter duration of illness, had a significantly lower haematocrit, and a significantly higher parasite burden.

\section{Clinical features of children with persistent early-appearing anaemia}

\section{Frequency and age distribution of children with persistent early-appearing anaemia}

Sixty two of 540 children with normal haematocrit before treatment initiation had PEAA. PEAA occurred in 10 of 168 (6\%), 18 of $176(10.2 \%)$ and 34 of 196 children (17.3\%) treated with AA, AL and DHP, respectively - a proportion significantly higher in DHP-treated children $(p=0.003)$. PEAA was significantly more common in children aged 36 months and under compared with those aged $>36$ months [39 of 234 children $(16.7 \%)$ versus 18 of 306 children $(7.5 \%)$, respectively; $p=0.002$; Fig. 2].

\section{Comparison of symptoms and signs at presentation and during PEAA}

The frequency of presenting symptoms and their severity were similar in the 478 children without PEAA and the 62 children who subsequently developed PEAA (data not shown). Sixty one children $(98.4 \%)$ reported no symptom 1 week after its commencement. In these children, parasitaemia, fever and other symptoms cleared within 3 days of treatment initiation. The frequency of symptoms and signs on presentation and during PEAA are shown in Figure 3. Compared with symptoms at presentation, PEAA was accompanied by significantly fewer symptoms of fever, headache, runny nose, anorexia, cough and vomiting, and signs of pyrexia.

\section{Factors contributing to persistent early-appearing anaemia following artemisinin-based combination treatments}

A duration of illness $\leq 3$ days, enrolment haematocrit $<35 \%$, haematocrit 1 day after treatment initiation $<25 \%$, DAFH $\geq 6 \%$, and treatment with DHP independently predicted PEAA (Table 2).

\section{Recovery from persistent early-appearing anaemia}

On day 1 following treatment initiation, PEAA was mild or moderate in 43 and 3 children, respectively. On day 2, it was mild or moderate in 15 children and 1 child, respectively. On day 7, it was mild or moderate in 60 and 2 children, respectively. During a follow-up period of 42 days, 7 children did not recover from their PEAA. The proportions of children who did not recover from their PEAA were similar with all three treatments [ 1 of 10 children $(10 \%)$ versus 4 of 18 children $(22.2 \%)$ versus 2 of 34 children $(5.9 \%)$ treated 


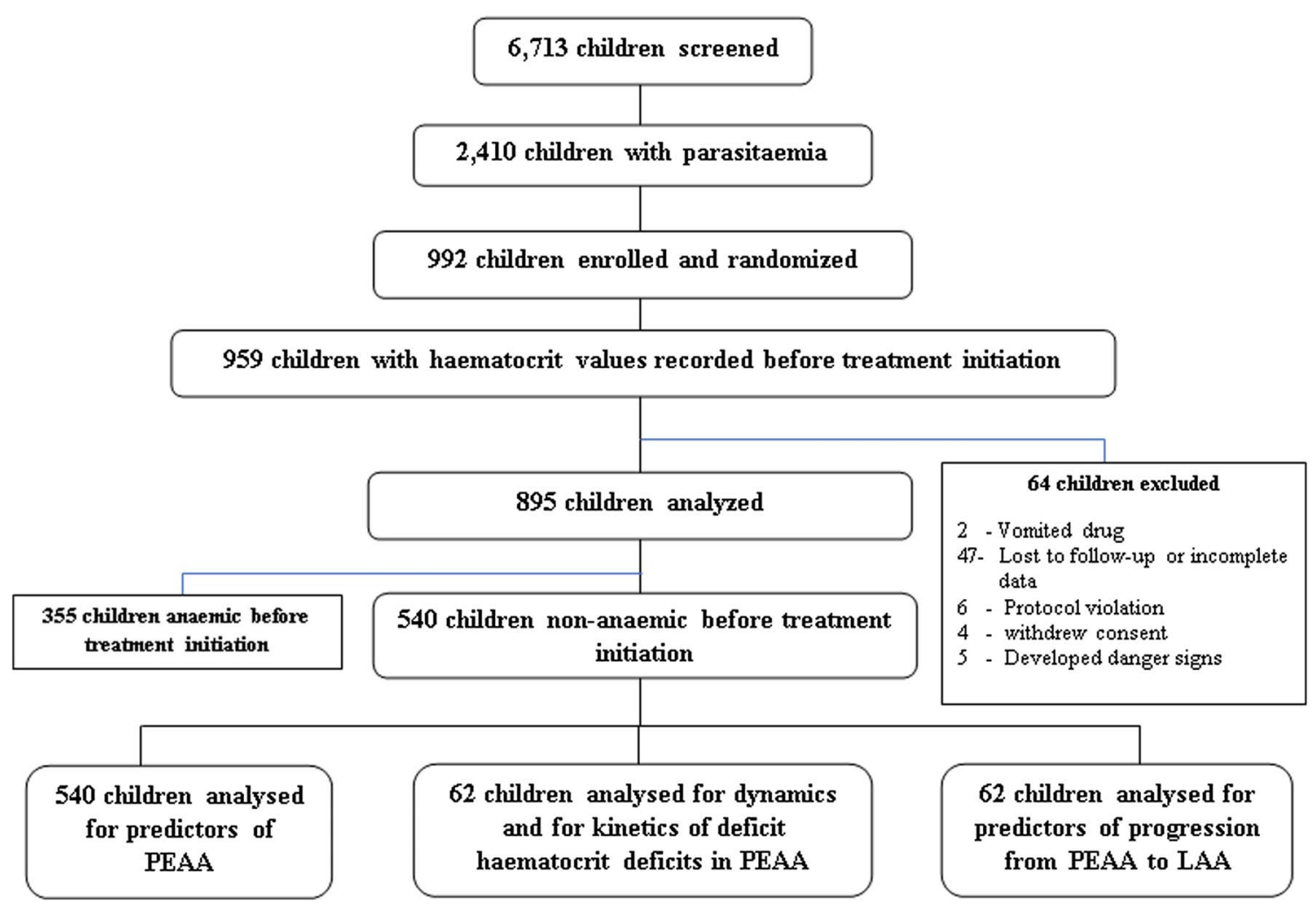

Figure 1. Study flowchart. PEAA, persistent early-appearing anaemia; LAA, late-appearing anaemia.

Table 1. Baseline characteristics of the children evaluated.

\begin{tabular}{|c|c|c|c|c|}
\hline \multirow[t]{2}{*}{ Parameters } & \multicolumn{3}{|c|}{ Persistent early-appearing anaemia } & \multirow[t]{2}{*}{$p$-value } \\
\hline & No $(n=478)$ & Yes $(n=62)$ & $\operatorname{ALL}(n=540)$ & \\
\hline Female $(\%)$ & $223(46.7)$ & $30(48.4)$ & $253(46.9)$ & 0.9 \\
\hline \multicolumn{5}{|l|}{ Age } \\
\hline$\leq 12$ months $(\%)$ & $28(5.9)$ & $6(9.7)$ & $34(6.3)$ & 0.38 \\
\hline$>12-36$ months $(\%)$ & $167(34.9)$ & $33(53.2)$ & $200(37)$ & 0.007 \\
\hline$>36$ months $(\%)$ & $283(59.2)$ & $23(37.1)$ & $306(56.7)$ & 0.002 \\
\hline Temperature $>37.4{ }^{\circ} \mathrm{C}(\%)$ & $308(64.4)$ & $40(65.2)$ & $348(64.4)$ & 1.0 \\
\hline Haematocrit $>35 \%$ & $172(36)$ & $9(14.5)$ & $181(33.5)$ & 0.001 \\
\hline \multicolumn{5}{|l|}{ Parasitaemia $\left(\mu \mathrm{L}^{-1}\right)$} \\
\hline$\leq 25,000(\%)$ & $271(56.7)$ & $25(40.3)$ & $296(54.8)$ & 0.02 \\
\hline$>25,000-50,000(\%)$ & $81(16.9)$ & $13(21)$ & $94(17.4)$ & 0.54 \\
\hline$>50,000-100,000(\%)$ & $79(16.5)$ & $13(21)$ & $92(17)$ & 0.49 \\
\hline$>100,000(\%)$ & $47(9.8)$ & $11(17.7)$ & $58(10.7)$ & 0.09 \\
\hline \multicolumn{5}{|l|}{ Mean value $(95 \% \mathrm{CI})$} \\
\hline Age (month) & $41.3(39.8-42.7)$ & $35.1(31.1-39.1)$ & $40.6(39.2-41.9)$ & 0.005 \\
\hline Weight (kg) & $13.8(13.4-14.2)$ & $11.6(10.8-12.5)$ & $13.6(13.2-13.9)$ & $<0.0001$ \\
\hline Duration of illness (day) & $4(3.6-4.3)$ & $2.8(2.2-3.5)$ & $3.8(3.5-4.2)$ & 0.003 \\
\hline Temperature $\left({ }^{\circ} \mathrm{C}\right)$ & $37.9(37.7-38)$ & $37.9(37.6-38.2)$ & $37.9(37.8-40)$ & 0.64 \\
\hline Haematocrit $(\%)$ & $33.8(33.5-34.1)$ & $32.1(31.5-32.7)$ & $33.6(33.3-33.9)$ & $<0.0001$ \\
\hline Geometric mean parasitaemia $\left(\mu \mathrm{L}^{-1}\right)$ & $16,175(14,284-18,316)$ & $28,427(20,406-39,600)$ & $17,257(15,350-19,401)$ & 0.003 \\
\hline
\end{tabular}

with AA, AL or DHP, respectively; $p=0.21]$. Overall, mean of time to recovery from PEAA was 17.4 days (95\% CI $15.5-19.4, n=55)$ and it was similar with all three treatments [15.9 days (95\% CI 13-18.7, $n=9)$ versus 20.7 days (95\% CI $15.5-26, n=14)$ versus 16.4 days $(95 \%$ CI 14-18.9, $n=32$ ) in AA-, AL- and DHP-treated children, respectively; $p=0.14]$.

\section{Other dynamics of recovery from PEAA}

On day 7, overall deficit from pre-treatment haematocrit was $5.7 \%(95 \%$ CI $4.8-6.6)$ and it was similar with all three treatments [5.4\% (95\% CI 3-7.2, $n=10)$ versus $5.4 \%(95 \%$ CI $4.2-6.6, n=18)$ versus $6 \%(95 \%$ CI $4.8-7.5, n=34)$, in AA-, AL- and DHP-treated children, respectively; $p=0.77]$. 


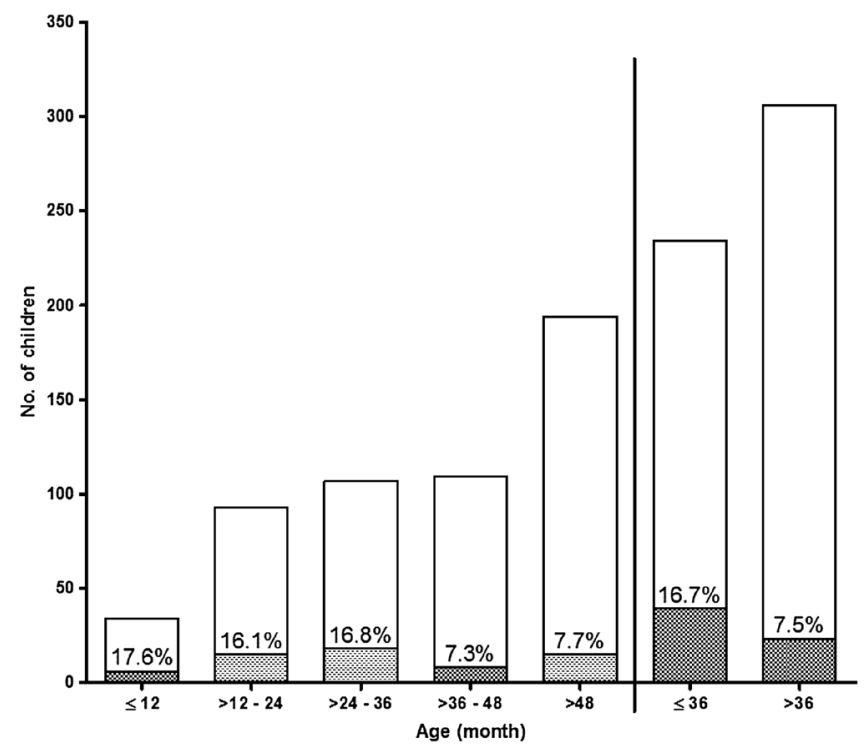

Figure 2. Frequency and age distribution of children with persistent early-appearing anaemia following initiation of artemisinin-based combination treatments of uncomplicated infections.

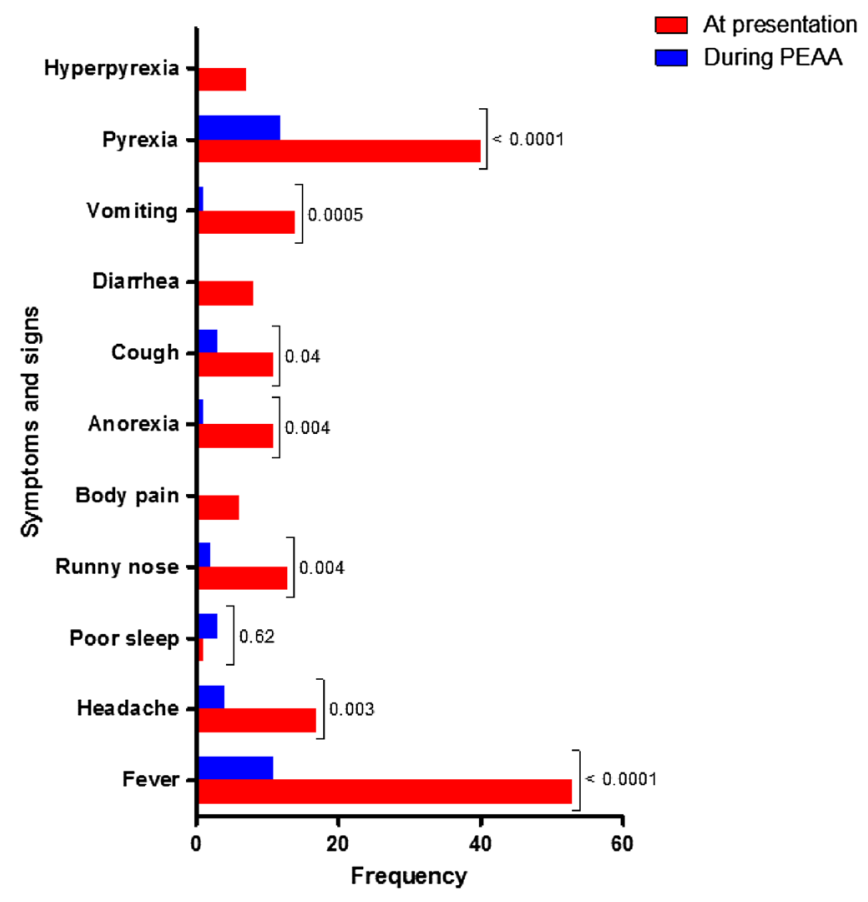

Figure 3. Symptoms and signs before treatment and during persistent early-appearing anaemia in children treated with artesunate-amodiaquine, artemether-lumefantrine or dihydroartemisininpiperaquine. PEAA, persistent early-appearing anaemia.

\section{(a) Time to $50 \%$ reduction of DIHFB}

Overall, mean time to $50 \%$ reduction in DIHFB ( $\left.T_{50 \text { dihfb }}\right)$ was 12.1 days (95\% CI 9.6-14.2, $n=59)$ and it was similar with all three treatments [11.4 days (95\% CI 8.2-14.6, $n=10)$ versus 15.4 days $(95 \%$ CI $9.9-20.9, n=17)$ versus 10.5 days $(95 \%$ CI 8.6-12.5, $n=32$ ), in AA-, AL- and DHP-treated children, respectively, $p=0.09]$.

\section{(b) Time to $90 \%$ reduction of DIHFB}

Overall, mean time to $90 \%$ reduction in DIHFB ( $T_{90 \text { dihfb }}$ ) was 16.7 days (95\% CI 14.9-18.4, $n=53)$ and it was significantly longer in AL-treated compared with AA- or DHP-treated children [20.5 days (95\% CI 15.8-25.2, $n=16$ ) versus 15.4 days (95\% CI 12.8-18, $n=10)$ versus 14.9 days (95\% CI $13.2-16.6, n=27)$, respectively, $p=0.01$ ]. Time to $90 \%$ reduction in haematocrit deficit was similar in AA- and DHP-treated children $(p=0.98)$.

\section{Kinetics of the disposition of the deficit in haematocrit from baseline}

The time-course of percentage decrease and of the disposition of DIHFB are shown in Figure 4. Mean percentage decrease in DIHFB was $18.4 \%$ (range $3-40, n=53$ ), $18.8 \%$ (range 3.3-42.9, $n=62$ ), 18.9\% (range 3.7-36.8, $n=62$ ), $17.7 \%$ (range 3.7-46.9, $n=62$ ), 16.6\% (range 3.2-38.7, $n=25$ ), $11.9 \%$ (range 3.3-13.4, $n=10$ ), 13.4\% (range 3.3$19.4, n=9$ ), $9.3 \%$ (range $6.7-13.9, n=9$ ) and $16.1 \%$ (range $10-25, n=8$ ) on days $1,2,3,7,14,21,28,35$, and 42, respectively (Fig. 4A). Maximum deficit occurred between 2 and 3 days after treatment initiation and it declined gradually thereafter (Fig. 4B). Overall, mean $\mathrm{AUC}_{\text {dihfb }}$ was $87.4 \%$ day $(95 \%$ CI 70.5-104.1, $n=62$ ) and it was similar for all three treatments [72.6\% day (95\% CI 34.1-111.1, $n=10)$ versus $104.3 \%$ day (95\% CI $68.8-139.9, n=18)$ versus $82.7 \%$ day (95\% CI 59.6-105.9, $n=34$ ), in AA-, AL- and DHP-treated children, respectively, $p=0.4$ ].

Declines in DIHFB were monoexponential with overall mean estimated half-time of 3.9 days (95\% CI 2.5-5.1, $n=62$, Fig. 5). Mean estimated half-time was similar with all three treatments [2.2 days $(95 \%$ CI $1.5-2.9, n=10)$ versus 5.1 days (95\% CI 1.8-8.4, $n=18)$ versus 3.7 days (95\% CI 2.1-5.3, $n=34$ ) in AA-, AL- and DHP-treated children, respectively; $p=0.45]$. The other kinetic parameters of the disposition of DIHFB are summarised in Table 3. These parameters are similar with all three treatments (Table 3).

\section{Relationship between time to reduction of deficit in haematocrit from baseline and half-time of haematocrit deficit}

There was a significant positive correlation between the following parameters: half-time of DIHFB and time to $50 \%$ reduction in DIHFB $(r=0.54, p<0.0001, n=57)$; half-time of DIHFB and time to $90 \%$ reduction in DIHFB ( $r=0.54$, $p<0.0001, n=53$ ); half-time of DIHFB and time to recovery from PEAA $(r=0.37, p=0.005, n=55)$; and 5 multiples of half-time of DIHFB and AnRT ( $r=0.33, p=0.01, n=55)$. The mean ratio of AnRT to mean of half-time of DIHFB $\left(t_{1 / 2 \mathrm{dihfb}}\right)$ was 7.1 (95\% CI 6.1-8.1). In Bland-Altman analyses, there were narrow limits of agreement between AnRT and 4, 5 or 6 multiples of half-time of DIHFB (Fig. 6). The limits of agreement were -28.4 to $32.8,-39.8$ to 36.6 and -51.4 to 40.6 at 4,5 or 6 multiples of half-time of haematocrit deficit, respectively. The bias at the multiples of 4,5 or 6 half-time was statistically insignificant $(p=0.29,0.55$ or 
Table 2. Predictors of persistent early-appearing anaemia in acutely malarious $<5$-year-old children following initiation of artemisinin-based combination treatments.

\begin{tabular}{|c|c|c|c|c|c|c|}
\hline Variable & Total no. & No. with PEAA & OR $(95 \% \mathrm{CI})$ & $p$ value & $\operatorname{AOR}(95 \% \mathrm{CI})$ & $p$ value \\
\hline \multicolumn{7}{|l|}{ Gender } \\
\hline Female & 253 & 30 & 1 & & & \\
\hline Male & 287 & 32 & $0.9(0.5-1.6)$ & 0.9 & - & - \\
\hline \multicolumn{7}{|l|}{ Age (month) } \\
\hline$>36$ & 306 & 23 & 1 & & 1 & \\
\hline$\leq 36$ & 234 & 39 & $2.5(1.4-4.3)$ & 0.002 & $1.8(0.5-4.3)$ & 0.18 \\
\hline \multicolumn{7}{|c|}{ Duration of illness (day) } \\
\hline$>3$ & 185 & 17 & 1 & & 1 & \\
\hline$\leq 3$ & 180 & 30 & $2.0(1.0-3.7)$ & 0.048 & $2.9(1.1-7.4)$ & 0.03 \\
\hline \multicolumn{7}{|c|}{ History of fever at presentation } \\
\hline Absent & 90 & 9 & 1 & & & \\
\hline Present & 450 & 53 & $1.2(0.6-2.5)$ & 0.73 & - & - \\
\hline \multicolumn{7}{|c|}{ Temperature at presentation $\left({ }^{\circ} \mathrm{C}\right)$} \\
\hline$\leq 37.4$ & 192 & 22 & 1 & & & \\
\hline$>37.4$ & 348 & 40 & $1.0(0.6-1.7)$ & 1.0 & - & - \\
\hline \multicolumn{7}{|c|}{ History of fever on day 1} \\
\hline Absent & 446 & 55 & 1 & & & \\
\hline Present & 94 & 7 & $0.6(0.3-1.3)$ & 0.24 & - & - \\
\hline \multicolumn{7}{|c|}{ Temperature on day $1\left({ }^{\circ} \mathrm{C}\right)$} \\
\hline$\leq 37.4$ & 480 & 55 & 1 & & & \\
\hline$>37.4$ & 60 & 7 & $1.0(0.4-2.4)$ & 1.0 & - & - \\
\hline \multicolumn{7}{|c|}{ Enrolment haematocrit $(\%)$} \\
\hline$\geq 35$ & 181 & 9 & 1 & & 1 & \\
\hline$<35$ & 359 & 53 & $3.3(1.6-6.9)$ & 0.001 & $4.6(1.6-13.1)$ & 0.005 \\
\hline \multicolumn{7}{|c|}{ Haematocrit on day $1(\%)$} \\
\hline$\geq 25$ & 492 & 42 & 1 & & 1 & \\
\hline$<25$ & 48 & 20 & $7.7(4-14.7)$ & $<0.0001$ & $3.5(1.1-11.4)$ & 0.03 \\
\hline \multicolumn{7}{|l|}{ DAFH $(\%)$} \\
\hline$<6$ & 333 & 17 & 1 & & 1 & \\
\hline$\geq 6$ & 207 & 45 & $5.2(2.9-9.3)$ & $<0.0001$ & $5.7(2.1-15.5)$ & 0.001 \\
\hline \multicolumn{7}{|c|}{ Enrolment parasitaemia $(/ \mu \mathrm{L})$} \\
\hline$\leq 75,000$ & 454 & 45 & 1 & & 1 & \\
\hline$>75,000$ & 86 & 17 & $2.2(1.2-4.1)$ & 0.02 & $1.3(0.4-4.1)$ & 0.65 \\
\hline \multicolumn{7}{|c|}{ Asexual parasitaemia on day 1} \\
\hline Absent & 209 & 24 & 1 & & & \\
\hline Present & 331 & 38 & $1.0(0.6-1.7)$ & 1.0 & - & - \\
\hline \multicolumn{7}{|c|}{ Asexual parasitaemia on day 2} \\
\hline Absent & 422 & 51 & 1 & & & \\
\hline Present & 118 & 11 & $0.7(0.4-1.5)$ & 0.5 & - & - \\
\hline \multicolumn{7}{|c|}{ Parasite clearance time (day) } \\
\hline$\leq 2$ & 418 & 51 & 1 & & & \\
\hline$>2$ & 122 & 11 & $0.7(0.4-1.4)$ & 0.42 & - & - \\
\hline \multicolumn{7}{|c|}{ Parasite reduction ratio on day 1} \\
\hline$\leq 25,000$ & 453 & 44 & 1 & & & \\
\hline$>25,000$ & 87 & 18 & $1.4(0.8-2.6)$ & 0.31 & - & - \\
\hline \multicolumn{7}{|c|}{ Parasite reduction ratio on day 2} \\
\hline$\leq 25,000$ & 339 & 31 & 1 & & 1 & \\
\hline$>25,000$ & 201 & 31 & $1.8(1.1-3.1)$ & 0.04 & $1.2(0.5-3.1)$ & 0.7 \\
\hline \multicolumn{7}{|c|}{ Drug treatment } \\
\hline AA & 168 & 10 & 1 & & 1 & \\
\hline $\mathrm{AL}$ & 176 & 18 & $1.8(0.8-4.0)$ & 0.22 & - & - \\
\hline DHP & 196 & 34 & $3.3(1.6-6.9)$ & 0.002 & $4.3(1.6-11.5)$ & 0.004 \\
\hline
\end{tabular}

DAFH, drug attributable fall in haematocrit; DHP, dihydroartemisinin-piperaquine; AL, artemether-lumefantrine; AA, artesunateamodiaquine; OR, odds ratio; AOR, adjusted odds ratio; PEAA, persistent early appearing anaemia. 

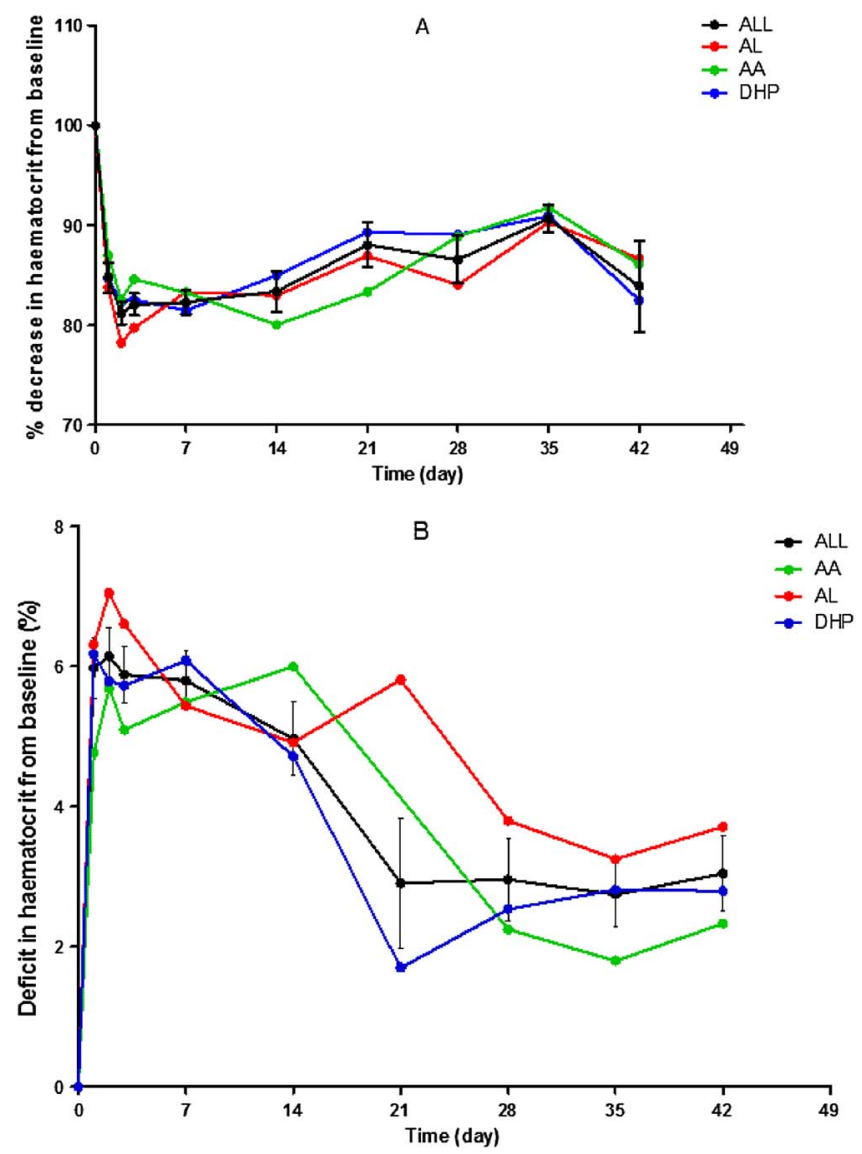

Figure 4. Time-course of percentage decrease (A) and of deficit in haematocrit (B) from baseline in all children (black line) and in those treated with artesunate-amodiaquine (green line), artemether-lumefantrine (red line) or dihydroartemisinin-piperaquine (blue line). Values are means and standard errors of mean; measures of dispersion have been included only in black plots for clarity.

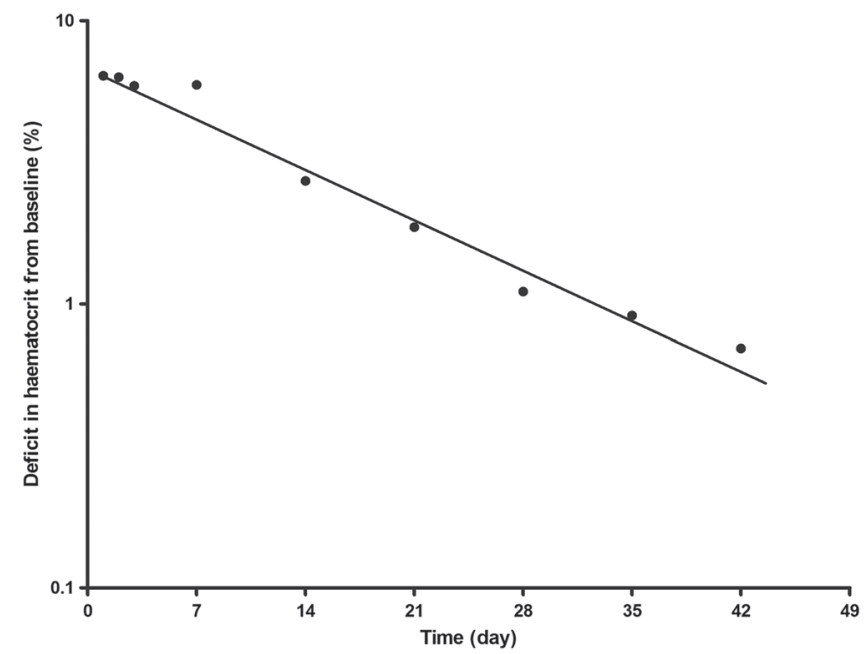

Figure 5. Semilogarithmic plot of deficit in haematocrit from baseline versus time in all children who developed persistent early- appearing anaemia following initiation of treatment with artesunate-amodiaquine, artemether-lumefantrine or dihydroartemisinin- piperaquine.
0.1 , respectively). However, there was statistically significant bias at multiples of 7 half-time of DIHFB ( $p=0.02$, Fig. 6).

\section{Relationship between persistent early-appearing anaemia and late-appearing anaemia}

Ten of the 55 children (18\%) who recovered from their PEAA after day 14 subsequently progressed to asymptomatic LAA (Table 4). The mean of time from recovery from PEAA to onset of LAA was 12 days. Proportions of children who recovered from their PEAA and subsequently progressed to LAA were significantly lower in children treated with DHP compared with AA- or AL- treated children (2 of 34 children (5.9\%) versus 4 of 10 children (40\%) versus 4 of 18 children (22.2\%), respectively; $p=0.02$ ). Nadir haematocrit during PEAA was similar with nadir haematocrit during LAA (Table 4). Following initiation of treatment, the mean of haematocrit, at all times in these children was $<30 \%$. Six of the 10 children who developed LAA did not recover from their LAA on day 42 of follow-up.

\section{Factors contributing to progression from persistent early-appearing anaemia to late- appearing anaemia following artemisinin-based combination treatments}

In a univariate analysis, female gender [odds ratio $(\mathrm{OR})=5.5(95 \% \mathrm{CI} 1.1-28.2)]$ and treatment with $\mathrm{AA}$ $[\mathrm{OR}=10.7$ (95\% CI 1.6-71.9) $]$ were significantly associated with progression from PEAA to LAA $(p=0.04$ and 0.02 , respectively). In a multivariate analysis, none of the associated factors independently predicted progression from PEAA to LAA [adjusted odds ratio $(\mathrm{AOR})=4.1$ (95\% CI 0.4-45.3, $p=0.25)$ and $\mathrm{AOR}=6.7(95 \%$ CI $0.9-50.5, p=0.07)$ for female gender and treatment with AA, respectively].

\section{Adverse events}

Sixty one of 540 children $(11 \%)$ reported at least one adverse event in the 1 week following initiation of treatment. The proportions of children reporting adverse events were similar in those with [7 of 62 children (11\%)] and those without [54 of 478 children (9\%)] PEAA. Reported adverse events were indistinguishable from those reported at presentation and consisted mainly of headache, nausea, cough or fever.

\section{Discussion}

In this study of children with uncomplicated falciparum malaria conducted over a period of 2 years, 62 of 540 children (11.5\%) developed PEAA following treatment with AA, AL or DHP. Virtually all of the children with PEAA were asymptomatic. The asymptomatic nature of the anaemia made it difficult, in the absence of haematocrit estimation, to make a diagnosis of PEAA. In addition, without intervention, many of the children (89\%) recovered from PEAA, but about $18 \%$ of those who recovered progressed to late-appearing anaemia. 
Table 3. Kinetic parameters of the disposition of the deficit in haematocrit from baseline in children with persistent early-appearing anaemia following initiation of treatment.

\begin{tabular}{|c|c|c|c|c|c|}
\hline Parameters & $\begin{array}{l}\text { Artesunate-amodiaquine } \\
(n=10)\end{array}$ & $\begin{array}{l}\text { Artemether-lumefantrine } \\
\qquad(n=18)\end{array}$ & $\begin{array}{l}\text { Dihydroartemisinin-piperaquine } \\
(n=34)\end{array}$ & $\begin{array}{c}\text { ALL } \\
(n=62)\end{array}$ & $p$ value \\
\hline \multicolumn{6}{|l|}{$\mathrm{Cmax}_{\mathrm{dihfb}}(\%)$} \\
\hline Mean $(95 \% \mathrm{CI})$ & $6.2(3.8-8.6)$ & $8.4(6.8-10.1)$ & $7.5(6.3-8.7)$ & $7.6(6.7-8.4)$ & 0.25 \\
\hline \multicolumn{6}{|l|}{$\operatorname{Tmax}_{\text {dihfb }}$ (day) } \\
\hline Mean $(95 \%$ CI $)$ & $3.3(1.5-5.1)$ & $2.7(1.7-3.8)$ & $3.8(2.6-5.1)$ & $3.4(2.6-4.1)$ & 0.46 \\
\hline \multicolumn{6}{|l|}{$\mathrm{AUC}_{\mathrm{dihfb}}(\%$.day) } \\
\hline Mean $(95 \% \mathrm{CI})$ & $72.6(34.1-111.1)$ & $104.3(68.8-139.9)$ & $82(59.6-105.9)$ & $87.4(70.6-104.1)$ & 0.4 \\
\hline \multicolumn{6}{|l|}{$t_{1 / 2 \mathrm{dihfb}}(\mathrm{day})$} \\
\hline Mean $(95 \% \mathrm{CI})$ & $2.2(1.5-2.9)$ & $5.1(1.8-8.4)$ & $3.7(2.1-5.3)$ & $3.9(2.6-5.1)$ & 0.29 \\
\hline \multicolumn{6}{|l|}{$K_{\text {eldihfb }}\left(\right.$ day $\left.^{-1}\right)$} \\
\hline Mean $(95 \%$ CI) & $0.3(0.3-0.4)$ & $0.3(0.2-0.3)$ & $0.3(0.2-0.4)$ & $0.3(0.3-0.4)$ & 0.26 \\
\hline \multicolumn{6}{|l|}{ CLp $_{\text {dihfb }}(\% /$ day) } \\
\hline Mean $(95 \%$ CI) & $0.7(0.2-1.2)$ & $0.4(0.3-0.4)$ & $0.6(0.4-0.8)$ & $0.6(0.5-0.7)$ & 0.13 \\
\hline \multicolumn{6}{|l|}{$\mathrm{Vd}_{\mathrm{diHbfb}}(\mathrm{L} / \mathrm{Kg})$} \\
\hline Median (Range) & $0.16(0.04-0.95)$ & $0.17(0.06-0.43)$ & $0.19(0.06-0.62)$ & $0.17(0.04-0.95)$ & 0.8 \\
\hline
\end{tabular}

$\mathrm{Cmax}_{\mathrm{dihfb}}$, maximum deficit in haematocrit from baseline; $\mathrm{Tmax}_{\mathrm{dihfb}}$, time to reach maximum deficit in haematocrit from baseline; $\mathrm{AUC}_{\mathrm{dihfb}}$, area under the curve of deficit in haematocrit from baseline versus time; $t_{1 / 2 \mathrm{def}}$, elimination half-time of deficit in haematocrit from baseline; $K_{\text {eldihfb }}$, elimination rate constant of deficit in haematocrit from baseline; CLp $p_{\text {dihfb}}$, volume of blood completely cleared of the deficit in haematocrit from baseline; $\mathrm{Vd}_{\mathrm{diHbfb}}$, volume of distribution of the deficit in haemoglobin from baseline; L, litre; ALL, all children.
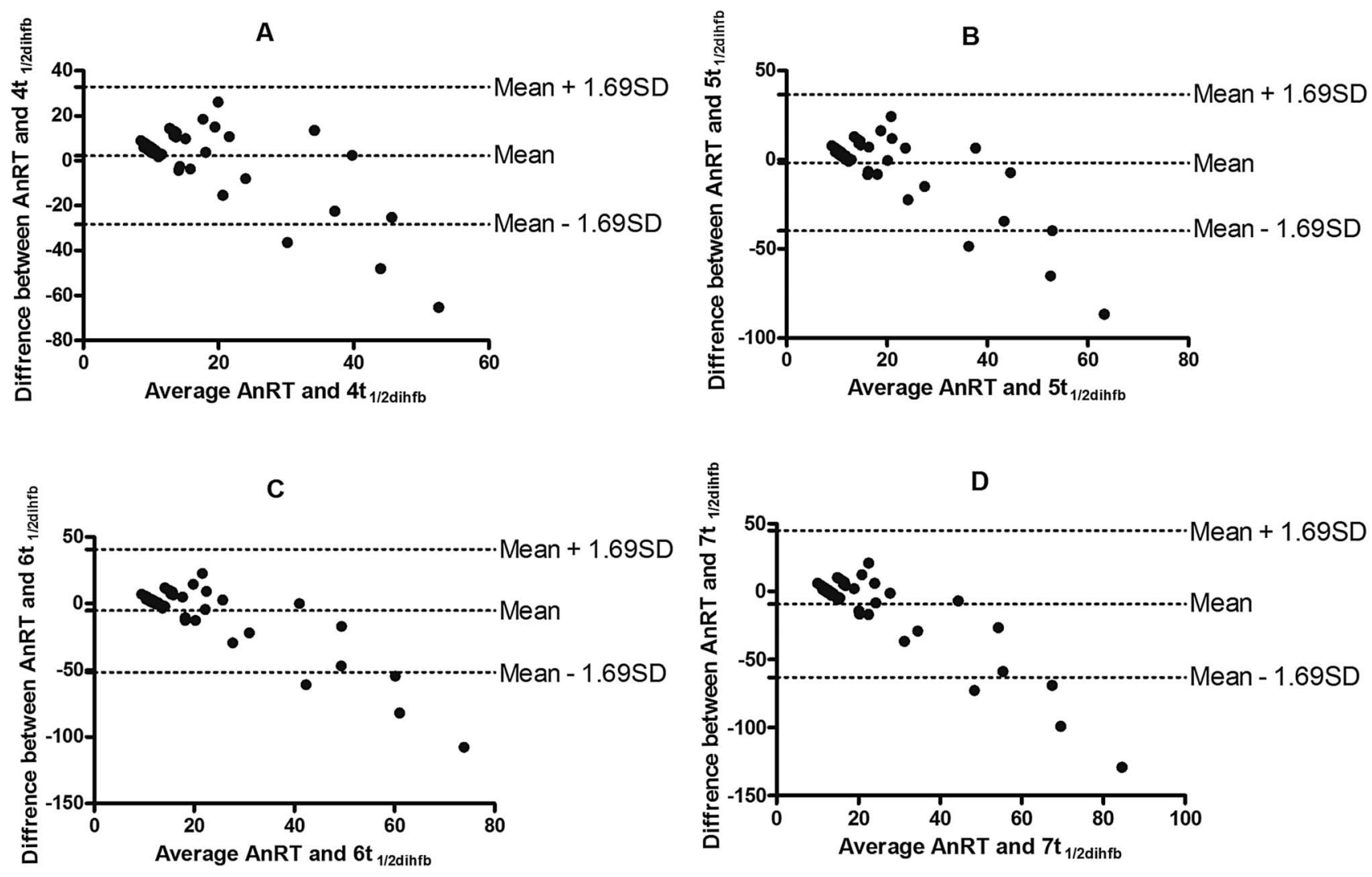

Figure 6. Bland-Altman plots of anaemia recovery time (AnRT) and multiples [4 (A), 5 (B), 6 (C) and 7 (D)] of half-time of deficit in haematocrit from baseline in children with persistent early-appearing anaemia. Biases were 2.23, $-1.57,-5.37$ and -9.17 for plots A, B, C and $\mathrm{D} ; p=0.29,0.55,0.09$ and 0.02 , respectively. The mean values \pm 1.96 standard deviation $(S D)$ of the differences are shown. dihfb, deficit in haematocrit from baseline.

Amongst the factors contributing to PEAA were young age, heavy parasite burden, and rapid reduction of heavy parasitaemias - the hallmark of artemisinins in artemisinin-sensitive infections. Collectively, these factors indicate that the interplay of host, parasite and drug factors made PEAA 2-6 times more likely than in those without these attributes [21]. Two points 
Table 4. Features of children who recovered from persistent early-appearing anaemia and who subsequently progressed to late-appearing anaemia.

\begin{tabular}{|c|c|c|c|c|c|c|c|c|c|c|c|}
\hline $\begin{array}{l}\text { Patient } \\
\text { (gender, } \\
\text { age) }\end{array}$ & $\begin{array}{c}\text { Parasitaemia } \\
\left(\mu \mathrm{L}^{-1}\right)\end{array}$ & $\begin{array}{c}\text { Pre- } \\
\text { treatment } \\
\text { HCT }(\%)\end{array}$ & $\begin{array}{c}\text { Antimalarial } \\
\text { treatment }\end{array}$ & PRRD2 & $\begin{array}{c}\text { PCT } \\
\text { (days) }\end{array}$ & $\begin{array}{l}\text { Nadir } \\
\text { HCT at } \\
\text { PEAA } \\
(\%)^{b, c}\end{array}$ & $\begin{array}{l}\text { Anaemia } \\
\text { recovery } \\
\text { time (day) }\end{array}$ & $\begin{array}{l}\text { Time to } \\
\text { LAA } \\
\text { (day) })^{\text {d }}\end{array}$ & $\begin{array}{c}\text { Nadir } \\
\text { HCT } \\
\text { at LAA } \\
(\%)^{b, c}\end{array}$ & $\begin{array}{c}\text { HCT on } \\
\text { day } 42 \\
(\%) \\
\text { I }\end{array}$ & $\begin{array}{c}\text { Time } \\
\text { between } \\
\text { recovery } \\
\text { and } \\
\text { LAA (day) }\end{array}$ \\
\hline $\begin{array}{l}\text { AD57 } \\
\quad(\mathrm{M}, 24 \mathrm{~m})\end{array}$ & 53,678 & 36 & DHP & 53,678 & 2 & 25 & 33 & 42 & 27 & 27 & 7 \\
\hline $\begin{array}{l}\mathrm{AD} 67 \\
\quad(\mathrm{~F}, 38 \mathrm{~m})\end{array}$ & 23,670 & 30 & AA & 23,670 & 1 & 26 & 13 & 35 & 26 & 30 & 21 \\
\hline $\begin{array}{l}\mathrm{IM} / \mathrm{E} / 47 \\
\quad(\mathrm{~F}, 59 \mathrm{~m})\end{array}$ & 4846 & 30 & AA & 4846 & 2 & 26 & 20 & 35 & 28 & 28 & 14 \\
\hline $\begin{array}{l}\mathrm{IM} / \mathrm{E} / 50 \\
\quad(\mathrm{~F}, 14 \mathrm{~m})\end{array}$ & 151,733 & 30 & AA & 151,733 & 2 & 25 & 20 & 42 & 25 & 25 & 21 \\
\hline $\begin{array}{l}\mathrm{IM} / \mathrm{E} / 66 \\
\quad(\mathrm{~F}, 59 \mathrm{~m})\end{array}$ & 27,965 & 30 & $\mathrm{AL}$ & 27,965 & 1 & 26 & 13 & 21 & 28 & 28 & 7 \\
\hline $\begin{array}{l}\mathrm{KN} / \mathrm{EN} / 90 \\
(\mathrm{~F}, 24 \mathrm{~m})\end{array}$ & 30,166 & 30 & DHP & 30,166 & 1 & 23 & 13 & 35 & 29 & 38 & 21 \\
\hline $\begin{array}{l}\text { KW10 } \\
\quad(F, 42 \mathrm{~m})\end{array}$ & 120,050 & 34 & $\mathrm{AL}$ & 5002 & 3 & 23 & 20 & 28 & 29 & 32 & 7 \\
\hline $\begin{array}{l}\text { SK18 } \\
\quad(M, 16 \mathrm{~m})\end{array}$ & 4842 & 33 & $\mathrm{AL}$ & 4842 & 2 & 26 & 13 & 35 & 25 & 26 & 21 \\
\hline $\begin{array}{l}\text { SK31 } \\
\qquad(F, 27 \mathrm{~m})\end{array}$ & 8538 & 31 & $\mathrm{AL}$ & 94.87 & 3 & 20 & 13 & 28 & 20 & 25 & 14 \\
\hline $\begin{array}{l}\text { SK46 } \\
\qquad(\mathrm{F}, 19 \mathrm{~m})\end{array}$ & 2004 & 31 & AA & 11.93 & 3 & 24 & 19 & 28 & 23 & - & 7 \\
\hline $\begin{array}{l}\text { Mean } \\
\quad(95 \% \mathrm{CI})\end{array}$ & $19,473^{\mathrm{a}}$ & $\begin{array}{c}31.5 \\
(30-33)\end{array}$ & & $5413^{\mathrm{a}}$ & $\begin{array}{c}1.8 \\
(1.3-2.5)\end{array}$ & $\begin{array}{c}24.4 \\
(23-25.8)\end{array}$ & $\begin{array}{c}16.9 \\
(13.5-21.1)\end{array}$ & $\begin{array}{c}32.3 \\
(27.7-37.6)\end{array}$ & $\begin{array}{c}26 \\
(23.9-28)\end{array}$ & $\begin{array}{c}27.8 \\
(25.6-32)\end{array}$ & $\begin{array}{c}12 \\
(8.6-18.1)\end{array}$ \\
\hline
\end{tabular}

m, month; AA, artesunate-amodiaquine; AL, artemether-lumefantrine; DHP, dihydroartemisinin-piperaquine; PCT, parasite clearance time; HCT, haematocrit; CI, confidence interval; PEAA, persistent early-appearing anaemia; LAA, late-appearing anaemia.

${ }^{a}$ Geometric mean.

${ }^{\mathrm{b}}$ No significant difference between nadir haematocrit during PEAA and LAA $(p=0.08)$.

${ }^{c}$ Virtually all patients were asymptomatic during PEAA and LAA.

d Time from commencement of treatment to occurrence of LAA.

may possibly help explain the persistence of anaemia for one or more weeks. First is continuing low grade haemolysis following the initial $18 \%$ decrease in haematocrit from baseline (Fig. 4), and second, slow recovery from the initial considerable falls in haematocrit following initiation of treatment. Thus, it is likely PEAA in uncomplicated falciparum malaria in children may be analogous to "persistent type post-treatment anaemia" following intravenous artesunate treatment of severe malaria in immunologically naïve adults [9]. In keeping with this analogy is the similar mean drop (18\% versus $16 \%)$ in baseline haematocrit three or more days after initiation of treatment in both situations (Fig. 4). Although DHP treatment predicted PEAA, PEAA was not related to the dose of dihydroartemisinin or piperaquine (data not shown). We have no explanation for this observation.

Although PEAA resulted in a mean of approximately $6 \%$ deficit in haematocrit $(17.7 \%$ drop from baseline) by 1 week after initiation of treatment, recovery of the deficit occurred in $89 \%$ of the children by 17-18 days after treatment initiation. Kinetically, recovery of the deficit was a first-order process with an estimated mean half-time of 4 days. If after 4 or 5 half-times 94 or $97 \%$, respectively of a first-order process would have been completed [17], it follows that approximately
16-20 days would be required for recovery from ACTs-related PEAA. Thus, there is correlation and agreement between recovery from PEAA determined dynamically and kinetically in the same individual in the cohort of children we evaluated. The insignificant bias on Bland-Altman analyses, between AnRT and 4 or 5 multiples of half-times of DIHFB (Fig. 6) is in keeping with this conclusion. The agreement also indicates AnRT or 4,5 or 6 multiples of half-times of DIHFB can be used interchangeably in the same patient.

The other outcomes of asymptomatic PEAA included non-recovery from PEAA in $11 \%$ of the children, and after recovery, progression to asymptomatic LAA in another $18 \%$ of the children. Taken together, these outcomes suggest ACTs predisposed $27 \%$ of young non-anaemic children with malaria before treatment initiation to a relatively prolonged period of anaemia following initiation of treatment. ACTs may also predispose these children to chronic anaemia if the malaria infections are frequent and the time available for complete recovery from anaemia in between infections is insufficient [19]. Strategies to reduce the likelihood of ACT-related PEAA and its consequences are urgently required in young children and should include early diagnosis and prevention. Estimation of haematocrit or haemoglobin before treatment 
initiation, on the last day of direct observed therapy (DOT), and at 2 weeks after initiation of treatment should aid in the early diagnosis of PEAA.

It is likely some differences may exist in the time-course of anaemia following treatments with the three ACTs. For example, DHP treatment predicted PEAA but recovery from PEAA was not unduly prolonged. Children treated with DHP also had significantly reduced propensity of their recovered PEAA for subsequent progression to LAA when compared to those treated with AA or AL (Table 4). On the other hand, both AA- and AL-treated children appeared to have significantly lesser propensity to develop PEAA, perhaps due to lag-times for conversion of artesunate or artemether to dihydroartemisinin but the children have significantly higher propensity of their recovered PEAA to progress to LAA (Table 4). An important feature of AL-related anaemia is slow recovery from PEAA, which, in part, is evidenced by the significantly longer time to $90 \%$ reduction in DIHFB.

It is unclear why female gender and treatment with AA were significantly associated with progression to LAA of children who recovered from their PEAA. It is also unclear the mechanisms for progression of PEAA to LAA. Rapid reduction of parasitaemia, evidenced by a PRRD2 value $>25,000$ being significantly related to PEAA (Table 2), should result in generation, by the artemisinin components of ACTs, of a significant number of pitted red blood cells that may be destroyed 7-21 days after treatment initiation to produce LAA [9]. Quantification of once-infected red blood cells in those who progressed and in those who did not progress from PEAA to LAA may aid both in identification of the causes or mechanisms and the risk of progression. It is also possible that early destruction of once-infected red blood cells may contribute to producing PEAA from EAA.

The criterion for onset of anaemia in patients with PEAA within 2 days after initiation of treatment took into account an intra-erythrocytic cycle of approximately $48 \mathrm{~h}$, a period of exclusive treatment with study drugs and of maximum exposure to these drugs, and an end of time of complete or almost complete clearance of parasitaemia in sensitive infections. Collectively, these allow for evaluation of the contribution of host, parasite and drug factors to producing EAA and its persistence for one or more weeks after treatment initiation (see above). In this context, it is likely that, in the setting of a parasitaemia $<200,000 / \mu \mathrm{L}$, age $<5$ years, haematocrit $>30 \%$ before treatment initiation, a $>15 \%$ decrease in baseline (pre-treatment) haematocrit on day 2 and/or 3 with or without available raised plasma lactate dehydrogenase and/or low haptoglobin, a case definition of PEAA or ACT-related "persistent post-treatment anaemia syndrome" can be made in these children in the settings of intense transmission.

Use of the DIHFB as a method for kinetic analyses of recovery from PEAA allowed for demonstration of the monoexponential declines from peak deficit in haematocrit, the hallmark of a first-order process [17]. It also confirms recovery from PEAA is a first-order process. The method is similar to that for estimation of half-life of a drug in a one-compartment pharmacokinetic model following a constant rate intravenous infusion in which drug concentrations prior to attainment of steady state or plateau are subtracted from steady state or plateau concentration and plotted against time semilogarithmically [17]. In this model, declines in drug concentrations are monoexponential [17].

There are limitations of the present study. First is nondetermination of whether PEAA is haemolytic or nonhaemolytic. Measurement of plasma lactate dehydrogenase and/or haptoglobin would have assisted with this determination. Second is non-quantification of once-infected erythrocytes. Quantification would have permitted evaluation of their contribution to PEAA and its progression to LAA. Third is non-quantification of reticulocytes. Quantification would have allowed evaluation of the contribution of reticulocytopaenia to PEAA. In animals, artemisinins cause reticulocytopaenia by suppressing erythroblasts [5]. Forth is the non-measurement of plasma dihydroartemisinin levels and their relationship to PEAA, since treatment with DHP predicted PEAA and both artesunate and artemether are converted to dihydroartemisinin. Finally, in the estimation of $\mathrm{Vd}_{\mathrm{diHbfb}}$, we did not measure haemoglobin since the conversion of haematocrit to haemoglobin by a factor of three as suggested by Bain and Bates [1] may not hold true especially when haemoglobin values are low [4, 15].

In conclusion, asymptomatic PEAA is common in young non-anaemic children with malaria following initiation of ACTs. Its occurrence, or progression to LAA, may have implications for case and community management of anaemia and for anaemia control efforts in sub-Saharan Africa where ACTs have become first-line antimalarials. Recovery from PEAA is a first-order process.

Acknowledgements. We are grateful to the parents/guardians and the children who participated in the study. The efficacy study from which the present data were derived was funded by the Global Fund for Malaria, Tuberculosis and HIV and the US President's Malaria Initiative (USPMI).

\section{Conflict of interests}

The authors declare that they have no conflict of interests.

\section{Availability of data and materials}

The dataset supporting the findings of this article is available from the corresponding author upon request.

\section{Author contributions}

KA participated in conduct of the study, data collection and analysis, and manuscript preparation; $\mathrm{BF}, \mathrm{GN}$ and $\mathrm{CA}$ in data analysis and manuscript preparation; JCE, JA, RW, NJ, FF, GE, OM and SO in conduct and data collection; OAF and $\mathrm{CH}$ in data analysis and manuscript preparation; AIA, TA, $\mathrm{AB}$, OTA, OA, CO, and GOG in kinetic analyses and manuscript preparation; AS led the design, conduct, data collection and analysis, and manuscript preparation. All authors read and approved the final draft of the manuscript before submission. 


\section{References}

1. Bain BJ, Bates I. 2001. Basic haematological techniques, in Practical Haematology, Lewis SM, Bain BJ, Bates I, Editors. 9th edn. Edinburgh: Churchill Livingstone. p. 19-46.

2. Bland JM, Altman DG. 1986. Statistical methods for assessing agreement between two methods of clinical measurement. Lancet, I, 307-310.

3. Burri C, Ferrari G, Ntuku MN, Kitoto AF, Dupare S, Hugo P, Mitemba DK, Lengeler C. 2014. Short report: delayed anemia after treatment with injectable artesunate in Demographic Republic of the Congo: a manageable issue. American Journal of Tropical Medicine and Hygiene, 91, 821-823.

4. Carneiro IA, Drakeley CJ, Owusu-Agyei S, Mmbando B, Chadramohan D. 2007. Haemoglobin and haematocrit: is the threefold conversion valid for assessing anaemia in malariaendemic setting? Malaria Journal, 6, 67.

5. Clark RL, Brannen KC, Sanders JE, Hoberman AM. 2011. Artesunate and artelinic acid: association of embryotoxicity, reticulocytepenia, and delayed stimulation of hematopoiesis in pregnant rats. Birth Defects Research Part B Developmental and Reproductive Toxicology, 92, 52-68.

6. Crawley J. 2004. Reducing the burden of anemia in infants and young children in malaria-endemic countries of Africa. American Journal of Tropical Medicine and Hygiene, 71(Suppl. 2), 25-34.

7. Ebenebe JC, Ntadom G, Ambe J, Wammanda R, Jiya N, Finomo F, Emechebe G, Mokuolu O, Akano K, Agomo C, Happi C, Folarin OA, Oguche S, Useh F, Oyibo W, Abdulkadir M, Aderoyeje T, Ezeigwe NM, Sowunmi A. 2018. Efficacy of artemisinin-based combination treatments of uncomplicated falciparum malaria in under-five-year-old Nigerian children ten years after adoption as first-line antimalarials. American Journal of Tropical Medicine and Hygiene, 99, 649-664.

8. Epi Info Version 6. 1994. A word processing data base and statistics program for public health on IBM-compatible microcomputers. Atlanta, GA: Centers for Disease Control and Prevention.

9. Jauréguiberry S, Ndour PA, Roussel C, Ader F, Safeukui I, Nguyen M, Biligui S, Ciceron L, Mouri O, Kendjo E, Vray M, Angoulvant A, Mayaux J, Haldar K, Mazier D, Danis M, Caumes E, Thellier M, Buffet P. 2014. Postartesunate delayed hemolysis is a predictable event related to the lifesaving effect of artemisinins. Blood, 124, 167-175.

10. Medicines for Malaria Venture. 2013. Expert Group Meeting on delayed haemolytic anaemia following treatment with injectable artesunate. Geneva: WHO. http://www.mmv.org/newsroom/ events/expert-group-meeting-safety-profile-injectable-artesunate. Accessed 17 October 2013.

11. Menendez C, Fleming AF, Alonso PL. 2000. Malaria-related anaemia. Parasitology Today, 16, 469-476.

12. Nkuo-Akenji TK, Chi PC, Cho JF, Ndamukong KK, Sumbele I. 2006. Malaria and helminth co-infection in children living in a malaria endemic setting of Mount Cameroon and predictors of anemia. Journal of Parasitology, 92, 1191-1195.

13. Oguche S, Okafor HU, Watila I, Meremikwu M, Agomo P, Ogala W, Agomo C, Ntadom G, Banjo O, Okuboyejo T, Ogunrinde G, Odey F, Aina O, Sofola T, Sowunmi A. 2014. Efficacy of artemisinin-based combination treatments of uncomplicated falciparum malaria in under-five year-old Nigerian children. American Journal of Tropical Medicine and Hygiene, 91, 925-935.

14. Price R, Simpson JA, Noston F, Luxemburger C, Hkirjaroen L, ter Kuile FO, Chongsuphajasiddhi T, White NJ. 2001. Factors contributing to anaemia after uncomplicated falciparum malaria. American Journal of Tropical Medicine and Hygiene, $65,614-622$.
15. Quinto L, Apote JJ, Menedez C, Sacarla J, Aide P, Espasa A, Mandomando IL, Guinovart C, Macete E, Hirt R, Urassa H, Navia MM, Thompson R, Alonso PO. 2006. Relationship between haemoglobin and haematocrit in the definition of anaemia. Tropical Medicine and International Health, 11, $1295-1302$.

16. Rolling T, Agbenyega T, Issifou S, Adegnika AA, Sylverken J, Spahlinger D, Ansong D, Löhr SJ, Burchard GD, May J, Mordmuller B, Krishna S, Kremsner PG, Cramer JP. 2014. Delayed hemolysis after treatment with parenteral artesunate in African children with severe malaria - a double-center prospective study. Journal of Infectious Diseases, 209, 1921-1928.

17. Rowland M, Tozer TN. 1980. Clinical pharmacokinetics: concept and application. Lea and Febiger: Philadelphia, PA.

18. Schellenberg D, Schellenberg JRMA, Mushi A, de Savigny D, Mgalula L, Mbuya C, Victora CG. 2003. The silent burden of anaemia in Tanzanian children: a community-based study. Bulletin of the World Health Organization, 81, 581-590.

19. Sowunmi A, Akano K, Ayede AI, Ntadom G, Aderoyeje T, Adewoye EO, Fatunmbi B. 2016. Clinical illness and outcomes in Nigerian children with late-appearing anaemia after artemisinin-based combination treatment of uncomplicated falciparum malaria. BMC Infectious Diseases, 16, 240.

20. Sowunmi A, Akano K, Ayede AI, Ntadom G, Aderoyeje T, Adewoye EO, Fatunmbi B. 2015. A one-compartment constant rate intravascular infusion model for the evaluation of increases in haematocrit after artemisinin-based combination treatments of acute falciparum malaria in children. Malaria Control and Elimination, S1, S1-006.

21. Sowunmi A, Fatunmbi B, Akano K, Wewe OA, Agomo C, Finomo F, Ebenebe J, Jiya N, Ambe J, Wammanda R, Ntadom G, Mokuolu O, Emechebe G, Ezeigwe N, Ayede AI, Adewoye EO, Gbotosho GO, Folarin OA, Happi CT, Oguche S, Oyibo WA, Useh F. 2017. Factors contributing to anaemia in falciparum malaria in under five year-old Nigerian children ten years following adoption of artemisinin-based combination treatments. BMC Infectious Diseases, 17, 781.

22. Sowunmi A, Gbotosho GO, Happi CT, Fateye B. 2010. Factors contributing to anaemia after uncomplicated Plasmodium falciparum malaria in children. Acta Tropica, 113, 155-161.

23. Sowunmi A, Gbotosho GO, Happi CT, Folarin O, Okuboyejo T, Michael O, Fatunmbi B. 2011. Use of area under the curve to evaluate the effects of antimalarial drugs on malaria-associated anaemia after treatment. American Journal of Therapeutics, 18, 190-197.

24. SPSS Inc. 2011. SPSS for Windows Release 20.0 (standard version). Chicago, IL: SPSS Inc.

25. World Health Organization. 2000. Severe falciparum malaria. Transactions of Royal Society of Tropical Medicine and Hygiene, 94(Suppl. 1), 1-90.

26. World Health Organization. 2003. Assessment and monitoring of antimalarial drug. Efficacy for the treatment of uncomplicated falciparum malaria. Geneva: World Health Organizations. WHO/HTM/RBM/2003.50.

27. World Health Organization. 2009. Methods for surveillance for antimalarial drug efficacy. Geneva: World Health Organization.

28. World Health Organization. 2013. WHO information note on delayed haemolytic anaemia following treatment with artesunate. Geneva: World Health Organization.

29. World Health Organization. 2014. Severe malaria. Tropical Medicine and International Health, 19(Suppl. 1), 7-131.

30. Zoller T, Junghanss T, Kapaun A, Gjørup I, Richter J, Hugo-Persson M, Mørch K, Foroutan B, Suttorp N, Yürek S, Flick H. 2011. Intravenous artesunate for severe malaria in Travellers, Europe. Emerging Infectious Diseases, 17, 771-777. 
Cite this article as: Akano K, Fatunmbi B, Ntadom G, Ayede AI, Aderoyeje T, Bakre A, Alebiosu OT, Akpoborie O, Okafor C, Gbotosho GO, Folarin OA, Ebenebe JC, Ambe J, Wammanda R, Jiya N, Finomo F, Emechebe G, Mokuolu O, Agomo C, Oguche S, Happi C \& Sowunmi A. 2019. Clinical illness and outcomes in Nigerian children with persistent early-appearing anaemia following initiation of artemisinin-based combination treatments of uncomplicated falciparum malaria. Parasite 26, 56.

\section{- PARASTE}

An international open-access, peer-reviewed, online journal publishing high quality papers on all aspects of human and animal parasitology

Reviews, articles and short notes may be submitted. Fields include, but are not limited to: general, medical and veterinary parasitology; morphology, including ultrastructure; parasite systematics, including entomology, acarology, helminthology and protistology, and molecular analyses; molecular biology and biochemistry; immunology of parasitic diseases; host-parasite relationships; ecology and life history of parasites; epidemiology; therapeutics; new diagnostic tools.

All papers in Parasite are published in English. Manuscripts should have a broad interest and must not have been published or submitted elsewhere. No limit is imposed on the length of manuscripts.

Parasite (open-access) continues Parasite (print and online editions, 1994-2012) and Annales de Parasitologie Humaine et Comparée (1923-1993) and is the official journal of the Société Française de Parasitologie. 